\title{
Cross-sectional associations of plasma vitamin $D$ with cerebral $\beta$-amyloid in older adults at risk of dementia
}

Fati Nourhashemi $i^{1,2,3,4+}$, Claudie Hooper ${ }^{1 *}{ }^{*}$, Christelle Cantet ${ }^{1,2,3,4}$, Catherine Féart ${ }^{5}$, Isabelle Gennero ${ }^{6,7}$,

Pierre Payoux ${ }^{8,9}$, Anne Sophie Salabert ${ }^{8,9}$, Sophie Guyonnet ${ }^{1,2,3,4}$, Philipe De Souto Barreto ${ }^{1,2,3,4}$,

Bruno Vellas ${ }^{1,2,3,4}$ and for the Multidomain Alzheimer Preventive Trial/Data sharing Alzheimer (DSA) study group

\begin{abstract}
Background: Vitamin D deficiency is associated with an increased risk of Alzheimer's disease and increased beta-amyloid $(A \beta)$ in animals. Hence we sought to investigate the relationship between plasma 25-hydroxyvitamin $D$ $(25(\mathrm{OH}) \mathrm{D})$ and cerebral $\mathrm{A} \beta$ in older adults with subjective memory complaints.

Methods: This is a secondary analysis of the Multidomain Alzheimer Preventive Trial. Participants were 178 dementiafree individuals aged 70 years or older with data on plasma $25(\mathrm{OH}) \mathrm{D}$ and cerebral $\mathrm{A} \beta$ load assessed by $\left[{ }^{18} \mathrm{~F}\right]$-florbetapir positron emission tomography. Plasma $25(\mathrm{OH}) \mathrm{D}$ was measured at study baseline using a commercially available electro-chemiluminescence competitive binding assay. Standard uptake value ratios (SUVRS) were generated using the cerebellum as a reference. Brain regions assessed included the cortex, anterior cingulate, anterior putamen, caudate, hippocampus, medial orbitofrontal cortex, occipital cortex, parietal cortex, pons, posterior cingulate, posterior putamen, precuneus, semioval centre and temporal cortex. Associations were explored using fully adjusted multiple linear regression models.
\end{abstract}

Results: Participants had a mean (SD) age of 76.2 years (4.4) and $59.6 \%$ were female. The mean (SD) plasma 25(OH)D level was $22.4 \mathrm{ng} / \mathrm{ml}$ (10.8) and the mean (SD) cortical SUVR was $1.2(0.2)$. We did not find any cross-sectional associations $(p>0.05)$ between baseline $25(\mathrm{OH}) \mathrm{D}$ levels and $A \beta$ in any of the brain regions studied.

Conclusions: These preliminary results suggest that circulating $25(\mathrm{OH}) \mathrm{D}$ is not associated with cerebral $A \beta$ in older adults. Further longitudinal studies with the measurement of mid-life vitamin $D$ status are required to explore the relationship between vitamin $D$ and $A \beta$ accrual over time, thereby circumventing the shortfalls of a cross-sectional study.

Keywords: Vitamin D, Beta-amyloid, Alzheimer's disease, Positron emission tomography

\section{Background}

Vitamin D is a fat-soluble steroid hormone that seems crucial for brain health in humans [1-5]. Low vitamin D status is common amongst the elderly and is considered a major health problem [6-8]. Studies have shown that vitamin $\mathrm{D}$ insufficiency is associated with a higher risk of Alzheimer's disease (AD) [9-16] and accelerated cognitive decline $[12,17,18]$, although some conflicting

\footnotetext{
* Correspondence: claudie28@yahoo.com

${ }^{\dagger}$ Equal contributors

${ }^{1}$ Gérontopôle, Department of Geriatrics, Toulouse University Hospital,

Toulouse, France

Full list of author information is available at the end of the article
}

results are reported [19-21]. Randomized controlled trials (RCTs) investigating the effects of vitamin D supplementation (alone or in combination with other drugs) on cognitive decline and AD onset are limited [22-25] and have largely proven unsuccessful to date [22, 23, 25].

Despite the controversy surrounding the role of vitamin $\mathrm{D}$ in cognitive function and $\mathrm{AD}$, animal studies suggest that vitamin $\mathrm{D}$ hypovitaminosis results in increased brain beta-amyloid $(A \beta)[26]$ and vitamin $D$ promotes a reduction in $A \beta$ brain burden [27, 28]. In human studies, vitamin $D$ has been shown to increase plasma $A \beta$, particularly in older adults, suggestive of decreased brain $A \beta$ [29]. Furthermore, vitamin D

(C) The Author(s). 2018 Open Access This article is distributed under the terms of the Creative Commons Attribution 4.0 International License (http://creativecommons.org/licenses/by/4.0/), which permits unrestricted use, distribution, and 
status assessed through a dietary questionnaire has been associated with less $A \beta$ in $A D$-vulnerable brain regions in subjects at risk of $\mathrm{AD}[30,31]$. However, to the best of our knowledge, studies have not addressed the relationship between circulating vitamin $\mathrm{D}$ (measured biochemically) and cerebral $\mathrm{A} \beta$. Thus, we examined the cross-sectional associations between 25-hydroxyvitamin $\mathrm{D}(25(\mathrm{OH}) \mathrm{D})$, the major circulating form of vitamin $D$, and cerebral $A \beta$ in older adults at risk of dementia. We hypothesized that $25(\mathrm{OH}) \mathrm{D}$ would be inversely associated with $\mathrm{A} \beta$.

\section{Methods}

\section{The Multidomain Alzheimer Preventive Trial, ethics and} approval

Data were obtained from a $\left[{ }^{18} \mathrm{~F}\right]$-florbetapir positron emission tomography (PET) study carried out as an ancillary project to the Multidomain Alzheimer Preventive Trial (MAPT) [32] (ClinicalTrials.gov, NCT00672685), a large multicentre, phase III, randomized, placebo-controlled trial. The MAPT was designed to assess the effects of omega 3 polyunsaturated fatty acid ( $\mathrm{n}-3$ PUFA) supplementation alone or in combination with a multidomain intervention (involving nutritional and exercise counselling and cognitive training), compared to placebo, in slowing cognitive decline in older adults with subjective memory complaints $(n=1680)$. Both the MAPT and the ancillary $\left[{ }^{18} \mathrm{~F}\right]$-florbetapir PET study were approved by the ethics committee in Toulouse (CPP SOOM II) and written consent was obtained from all participants.

\section{Participants}

At inclusion, subjects were community-dwelling men and women without dementia, aged $\geq 70$ years, who met at least one of the following criteria: spontaneous memory complaints, limitation in executing $\geq 1$ Instrumental Activity of Daily Living, or slow gait speed $(\leq 0.8 \mathrm{~m} / \mathrm{s})$. Participants of this study were 180 individuals who had data on plasma 25(OH)D and cerebral $A \beta$ load. However, two participants were excluded from the present analysis because they had CDR $\geq 1$ (suggestive of dementia) at the clinical visit closest to PET-scan assessment. Thus, a total of 178 participants were included in the study described here.

\section{$\left[{ }^{18} \mathrm{~F}\right]$-Florbetapir positron emission tomography}

PET scans as a measure of cerebral $A \beta$ load were performed using $\left[{ }^{18} \mathrm{~F}\right]$-florbetapir as described previously [32, 33]. PET data acquisitions commenced $50 \mathrm{~min}$ after injection of a mean of $4 \mathrm{MBq} / \mathrm{kg}$ weight of $\left[{ }^{18} \mathrm{~F}\right]$ Florbetapir. Radiochemical purity of $\left[{ }^{18} \mathrm{~F}\right]$-Florbetapir was superior to $99.5 \%$. Regional standard uptake value ratios (SUVRs) were generated from semi-automated quantitative analysis with the whole cerebellum used as the reference region. Cortical-to-cerebellar SUVRs (cortical-SUVRs) were obtained using the mean signal of the predefined cortical regions: frontal, temporal, parietal, precuneus, anterior cingulate and posterior cingulate as described previously [34]. Other brain regions independently assessed were the anterior cingulate, anterior putamen, caudate, hippocampus, medial orbitofrontal cortex, occipital cortex, parietal cortex, pons, posterior cingulate, posterior putamen, precuneus, semioval centre and temporal cortex. A Quality Control procedure was carried out using a semi-quantification-based method. PET scans were performed an average of $18.1 \pm 8.8$ months after baseline.

\section{Measurement of 25(OH)D}

Total plasma 25(OH)D (D3 and D2 forms) was measured using a commercially available electro-chemiluminescence competitive binding assay (Cobas, Roche) in baseline plasma samples. In brief, plasma $(15 \mu \mathrm{l})$ was denatured to release bound $25(\mathrm{OH}) \mathrm{D}$ from vitamin $\mathrm{D}$ binding protein (VDBP). The sample was then incubated with recombinant ruthenium-labelled VDBP to enable complex formation. Biotinylated $25(\mathrm{OH}) \mathrm{D}$ was subsequently added and the entire complex became bound to the electrode through an interaction of biotin with streptavidin-coated micro-particles, which are captured on the electrode surface. Unbound substance was subsequently removed and a voltage was applied to the electrode which induced a chemiluminescent emission that was quantified using a Roche Cobas 8000 e602 analyser (Roche Diagnostics, Mannheim, Germany). The concentrations of 25(OH)D $(\mathrm{ng} / \mathrm{ml})$ were determined against a standard curve.

\section{Confounding variables}

We selected the following confounding variables on the basis of data availability and the literature on $\mathrm{AD}$ and vitamin D [35, 36]: age at PET-scan assessment, gender, body mass index (BMI), season of blood collection (four categories: autumn, winter, spring, summer), educational level, cognitive status assessed at the clinical visit closest to the PET scan (Mini Mental State Examination (MMSE): score out of 30), time interval (months) between baseline and the PET scan, MAPT group allocation (four groups: placebo, multidomain intervention, n-3 PUFA supplementation, multidomain intervention + n-3 PUFA supplementation) and apolipoprotein E $\varepsilon 4$ (ApoE ع4) genotype (carriers of at least one $\varepsilon 4$ allele versus non-carriers).

\section{Statistical analysis}

Descriptive characteristics are presented as mean \pm standard deviation (SD) or absolute values/percentages. The relationship between plasma $25(\mathrm{OH}) \mathrm{D}$ and cerebral $A \beta$ load was not an a-priori hypothesis of the MAPT. After completing the analysis of the primary hypotheses 
in the MAPT, we performed additional post-hoc analyses using multiple linear regression models to evaluate the cross-sectional relationships between plasma $25(\mathrm{OH}) \mathrm{D}$ and cerebral brain $A \beta$ load measured in SUVRs (both as continuous variables) adjusting for all confounders. We ran three separate sensitivity analyses in order to substantiate our main analysis exploring the relationship between $25(\mathrm{OH}) \mathrm{D}$ and cortical $\mathrm{A} \beta$. Firstly, we classified the $25(\mathrm{OH}) \mathrm{D}$ data according to the cut-off values $<20 \mathrm{ng} /$ $\mathrm{ml}, \geq 20$ but $\leq 30 \mathrm{ng} / \mathrm{ml}$ and $>30 \mathrm{ng} / \mathrm{ml}$ which are defined as $25(\mathrm{OH}) \mathrm{D}$ deficiency, insufficiency and sufficiency [37]. The cut-off value of $<10 \mathrm{ng} / \mathrm{ml}$, which has been associated with worse cognitive outcomes, was not used since there were only 16 out of 178 subjects (9\%) with $25(\mathrm{OH}) \mathrm{D}$ in this range. The class containing values of $25(\mathrm{OH})$ $\mathrm{D}>30 \mathrm{ng} / \mathrm{ml}$ was used as the reference. We then ran multiple linear regression analysis adjusted for all confounders. Secondly, we dichotomized the dependent variable, cortical $A \beta$ load, with a positivity threshold of mean cortical SUVR $\geq 1.17$ [33, 38] and then performed logistic regression adjusted for all confounders. Thirdly, we used de-seasonalized $25(\mathrm{OH}) \mathrm{D}$ values calculated according to the periodic function $y_{t}=B_{0}+B_{1} \sin (2 \pi t / 365)$ $+B_{2} \cos (2 \pi t / 365)[12,39]$ to assess the relationship between $25(\mathrm{OH}) \mathrm{D}$ and cortical $\mathrm{A} \beta$ (both as continuous variables) using multiple linear regression analysis adjusted for all confounders (minus season categorized into four classes). To explore the role of apolipoprotein $\mathrm{E}$ (ApoE) $\varepsilon 4$ genotype, the major risk factor for sporadic $\mathrm{SD}$ [40], on the association between $25(\mathrm{OH}) \mathrm{D}$ and cortical $\mathrm{A} \beta$ (both as continuous variables) we ran a linear regression analysis with the introduction of an interaction term between ApoE $\varepsilon 4$ genotype and $25(\mathrm{OH}) \mathrm{D}$. There was no correction for multiple comparisons: $p<0.05$ was considered statistically significant. Statistical analyses were performed using SAS software version 9.4 (SAS Institute Inc., Cary, NC, USA).

\section{Results}

\section{Sample characteristics}

Clinical and demographic characteristics of the study participants are presented in Table 1. The mean age of the participants was around 76 years and approximately $60 \%$ of the subjects were female. Participants exhibited a high educational level and just less than half had a CDR score of 0.5 . Approximately one-quarter of the subjects were ApoE $\varepsilon 4$ carriers. The mean (SD) plasma $25(\mathrm{OH}) \mathrm{D}$ level was $22.4 \mathrm{ng} / \mathrm{ml}(10.8)$ and the mean (SD) cortical SUVR was $1.2(0.2)$.

\section{Exploration of the relationship between 25(OH)D and cerebral $A \beta$}

Neither cortical $A \beta$ load nor $A \beta$ levels present in the anterior cingulate, anterior putamen, caudate, hippocampus,
Table 1 Participant characteristics

\begin{tabular}{|c|c|}
\hline Variable & $\begin{array}{l}\text { Value } \\
(n=178)\end{array}$ \\
\hline Age (years) & $76.2 \pm 4.4$ \\
\hline Sex, women & $106(59.6 \%)$ \\
\hline \multicolumn{2}{|l|}{ Education } \\
\hline No diploma or primary school certificate & 47 (26.6\%) \\
\hline Secondary education no high-school diploma & $49(27.7 \%)$ \\
\hline High school diploma & $24(13.6 \%)$ \\
\hline University level & $57(32.2 \%)$ \\
\hline \multicolumn{2}{|l|}{ MAPT group allocation } \\
\hline Multidomain intervention & 39 (21.9\%) \\
\hline n-3 PUFA supplementation & $42(23.6 \%)$ \\
\hline $\begin{array}{l}\text { Multidomain intervention and n-3 PUFA } \\
\text { supplementation }\end{array}$ & $49(27.5 \%)$ \\
\hline Placebo & $48(27.0 \%)$ \\
\hline \multicolumn{2}{|l|}{ Season of vitamin D measurement } \\
\hline Winter & $71(39.9 \%)$ \\
\hline Spring & $37(20.8 \%)$ \\
\hline Summer & $15(8.4 \%)$ \\
\hline Autumn & 55 (30.9\%) \\
\hline BMI $\left(\mathrm{kg} / \mathrm{m}^{2}\right)$ & $26.6 \pm 4.0$ \\
\hline CDR 0.5 & 79 (44.4\%) \\
\hline MMSE score (/30) & $28.3 \pm 1.6$ \\
\hline ApoE $\varepsilon 4$ carriers $^{a}$ & $42(25.6 \%)$ \\
\hline 25-Hydroxyvitamin D (ng/ml) & $22.4 \pm 10.8$ \\
\hline 25-Hydroxyvitamin $\mathrm{D}<20 \mathrm{ng} / \mathrm{ml}$ & $81(45.5 \%)$ \\
\hline 25 -Hydroxyvitamin $\mathrm{D} \geq 20 \mathrm{ng} / \mathrm{ml} \leq 30 \mathrm{ng} / \mathrm{ml}$ & $56(31.5 \%)$ \\
\hline 25-Hydroxyvitamin D> $30 \mathrm{ng} / \mathrm{ml}$ & $41(23.0 \%)$ \\
\hline Cortical SUVR & $1.2 \pm 0.2$ \\
\hline Cortical SUVR positive ( $\geq 1.17$ ) & $75(42.1 \%)$ \\
\hline
\end{tabular}

Age, CDR, BMI and MMSE score closest to the PET scan are presented Data expressed as mean \pm standard deviation or absolute value (percentage) $B M I$ body mass index, CDR Clinical Dementia Rating, MAPT Multidomain Alzheimer Preventive Trial, $n-3$ PUFA omega-3 polyunsaturated fatty acid, MMSE Mini Mental State Examination, ApoE apolipoprotein E, SUVR standard uptake ratio values

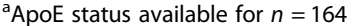

medial orbitofrontal cortex, occipital cortex, parietal cortex, pons, posterior cingulate, posterior putamen, precuneus, semioval centre and temporal cortex were associated with plasma 25(OH)D after adjustment for all confounders (Table 2).

\section{Sensitivity analysis}

Categorization of the 25(OH)D data and dichotomization of the $A \beta$ data showed comparable results to the main analysis using cortical $A \beta$ (Table 3). Exploring the relationship between de-seasonalized vitamin $D$ values and cortical $A \beta$ load also corroborated the main analysis using cortical $\mathrm{A} \beta$ (Table 3). 
Table 2 Exploration of the association of $25(\mathrm{OH}) \mathrm{D}$ with cerebral $A \beta$

\begin{tabular}{|c|c|c|c|c|c|c|}
\hline \multirow[t]{2}{*}{ Brain region } & \multicolumn{3}{|c|}{ Unadjusted model } & \multicolumn{3}{|c|}{ Adjusted model } \\
\hline & $B$ coefficient & SE & $p$ & $B$ coefficient & SE & $p$ \\
\hline Cortex & -0.001 & 0.001 & 0.587 & -0.001 & 0.001 & 0.376 \\
\hline Anterior cingulate & -0.001 & 0.002 & 0.378 & -0.002 & 0.002 & 0.325 \\
\hline Anterior putamen & 0.000 & 0.001 & 0.972 & -0.000 & 0.001 & 0.880 \\
\hline Caudate & -0.001 & 0.001 & 0.502 & -0.000 & 0.001 & 0.872 \\
\hline Hippocampus & 0.000 & 0.001 & 0.840 & 0.001 & 0.001 & 0.495 \\
\hline Medial orbitofrontal cortex & -0.000 & 0.001 & 0.928 & -0.000 & 0.001 & 0.794 \\
\hline Occipital cortex & -0.001 & 0.001 & 0.351 & -0.001 & 0.001 & 0.291 \\
\hline Parietal cortex & -0.000 & 0.001 & 0.930 & -0.001 & 0.001 & 0.662 \\
\hline Pons & 0.000 & 0.001 & 0.941 & 0.000 & 0.001 & 0.698 \\
\hline Posterior cingulate & -0.000 & 0.001 & 0.779 & -0.001 & 0.001 & 0.461 \\
\hline Posterior putamen & 0.000 & 0.001 & 0.623 & 0.000 & 0.001 & 0.822 \\
\hline Precuneus & -0.001 & 0.002 & 0.471 & -0.002 & 0.002 & 0.287 \\
\hline Temporal cortex & -0.001 & 0.001 & 0.479 & -0.001 & 0.001 & 0.240 \\
\hline Semioval centre & -0.001 & 0.001 & 0.646 & 0.000 & 0.001 & 0.803 \\
\hline
\end{tabular}

The unadjusted linear regression model in the main analysis included all 178 participants who underwent $\left[{ }^{18} \mathrm{~F}\right]$-florbetapir positron emission tomography imaging. Cortical-to-cerebellar standard uptake value ratios were obtained using the mean signal of the following predefined cortical regions: frontal, temporal, parietal, precuneus, anterior cingulate and posterior cingulate. Other brain regions were independently assessed for $A \beta$ in relation to the cerebellum as a reference region. The adjusted model contained fewer subjects $(n=176)$ due to missing data on confounders

$A \beta$ beta-amyloid, 25(OH)D 25-hydroxyvitamin D, SE standard error

\section{Exploratory analysis}

Next we explored the relationship between $25(\mathrm{OH}) \mathrm{D}$ and cortical $\mathrm{A} \beta$ as a function of $\mathrm{ApoE} \varepsilon 4$ status. However, the interaction between $25(\mathrm{OH}) \mathrm{D}$ and $\mathrm{ApoE} \varepsilon 4$ genotype was not associated with cortical $\mathrm{A} \beta$ load $(p=0.434)$.

\section{Discussion}

We have shown that vitamin $\mathrm{D}$ measured as $25(\mathrm{OH}) \mathrm{D}$ was not associated with cerebral $A \beta$ independently or as a function of ApoE $\varepsilon 4$ status. To the best of our knowledge, this is the first study to explore the associations between circulating plasma vitamin D (measured biochemically) and cerebral $\mathrm{A} \beta$.

Our findings were against our original hypothesis based on animal experiments [27, 28] and human studies using nutritional questionnaires to assess the associations between vitamin $\mathrm{D}$ status and cerebral $\mathrm{A} \beta[30,31]$. However, the participants of these human studies were younger and cognitively normal. It might also be that dietary questionnaires do not best capture vitamin D status especially in those with memory complaints. Moreover, sun exposure is the major source of vitamin D.

Table 3 Sensitivity analyses exploring the association of $25(\mathrm{OH}) \mathrm{D}$ with cerebral $A \beta$

\begin{tabular}{|c|c|c|c|c|c|c|}
\hline & \multicolumn{3}{|c|}{ Unadjusted model } & \multicolumn{3}{|l|}{ Adjusted model } \\
\hline & $\begin{array}{l}\text { B coefficient or } \\
\text { odds ratio* }\end{array}$ & SE or $95 \% \mathrm{Cl}^{*}$ & $p$ & $\begin{array}{l}\text { B coefficient or } \\
\text { odds ratio* }\end{array}$ & SE or $95 \% \mathrm{Cl}^{*}$ & $p$ \\
\hline \multicolumn{7}{|l|}{ 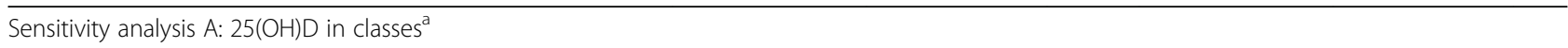 } \\
\hline $25(\mathrm{OH}) \mathrm{D}<20 \mathrm{ng} / \mathrm{ml}$ & 0.005 & 0.033 & 0.869 & 0.010 & 0.034 & 0.775 \\
\hline $25(\mathrm{OH}) \mathrm{D} \geq 20 \mathrm{ng} / \mathrm{ml} \leq 30 \mathrm{ng} / \mathrm{ml}$ & 0.061 & 0.036 & 0.089 & 0.039 & 0.035 & 0.273 \\
\hline \multicolumn{7}{|l|}{ Sensitivity analysis B: logistic regression ${ }^{\mathrm{b}}$} \\
\hline $25(\mathrm{OH}) \mathrm{D}<20 \mathrm{ng} / \mathrm{ml}$ & $1.021^{*}$ & $0.477,2.188^{*}$ & 0.957 & $1.038^{*}$ & $0.421,2.557^{*}$ & 0.936 \\
\hline $25(\mathrm{OH}) \mathrm{D} \geq 20 \mathrm{ng} / \mathrm{ml} \leq 30 \mathrm{ng} / \mathrm{ml}$ & $1.059^{*}$ & $0.468,2.395^{*}$ & 0.891 & $0.769^{*}$ & $0.299,1.978^{*}$ & 0.585 \\
\hline Sensitivity analysis C: de-seasonalized $25(\mathrm{OH}) \mathrm{D}$ (continuous) ${ }^{c}$ & -0.001 & 0.001 & 0.600 & -0.001 & 0.001 & 0.421 \\
\hline
\end{tabular}

${ }^{a}$ Multiple linear regression was run to explore the associations between cortical A $\beta$ and $25(\mathrm{OH}) \mathrm{D}$ classified according to the cut-off values $<20$ ng/ml, $\geq 20$ but $\leq$ $30 \mathrm{ng} / \mathrm{ml}$ and $>30 \mathrm{ng} / \mathrm{ml}$ adjusting for all confounders

${ }^{b}$ Logistic regression was performed with $A \beta$ dichotomized with a positivity threshold of mean cortical standard uptake value ratio $\geq 1.17$ and $25(\mathrm{OH}) \mathrm{D}$ in classes with adjustment for all confounders

'De-seasonalized $25(\mathrm{OH}) \mathrm{D}$ values were used to assess the relationship between cortical $A \beta$ and $25(\mathrm{OH}) \mathrm{D}$ both as continuous variables using a multiple linear regression model adjusted for all confounders. The adjusted models contained fewer subjects $(n=176)$ due to missing data on confounders

$A \beta$ beta-amyloid, $\mathrm{Cl}$ confidence interval, SE standard error, $25(\mathrm{OH}) \mathrm{D} 25$-hydroxyvitamin D 
Our findings are in line with those showing that vitamin $\mathrm{D}$ concentrations are not associated with cognitive decline or AD [19-21], although a number of reports to the contrary are published [9-18]. Considering that RCTs investigating the effects of vitamin D supplementation on brain health are negative to date [22, 23, 25], it could be hypothesized that observational studies reporting a significant association between vitamin $\mathrm{D}$ status and cognitive decline or $\mathrm{AD}$ risk might be prone to reverse causality bias. Alternatively, the failure of vitamin D trials might be attributed to the short duration of therapy or the sub-optimal timing of vitamin D supplementation. Timing has recently been highlighted as an important criterion in the relationship between vitamin $\mathrm{D}$ and cognition $[18,41]$. Indeed, vitamin D status mid-life has been associated with cognition 10 years later [42]. Thus, the duration and time window of vitamin $\mathrm{D}$ hypovitaminosis might dictate pathological changes associated with $\mathrm{AD}$ in older age. In the same vein, the assessment of cerebral $A \beta$ in later life does not provide information on the slow pathophysiological accrual of $A \beta$ [43] and the role of vitamin D. Perhaps as with cognition, mid-life vitamin $\mathrm{D}$ deficiency might contribute more to $A \beta$ deposition than vitamin $D$ deficiency in later life. Thus, in this study we might have failed to detect an association between vitamin $\mathrm{D}$ status and cerebral $\mathrm{A} \beta$ load due to the inappropriate timing of measurements; however, plasma samples in mid-life were not available in the MAPT to test further hypotheses.

It is also feasible that vitamin $\mathrm{D}$ hypovitaminosis is linked to cognitive decline via $\mathrm{A} \beta$-independent processes. Indeed, 25(OH)D insufficiency is associated with an increase in white matter abnormalities indicative of cerebrovascular disease $[44,45]$ and decreasing $25(\mathrm{OH})$ $\mathrm{D}$ plasma levels are associated with an increased risk of ischaemic stroke [46]. Thus, it is plausible that vitamin $\mathrm{D}$ might be associated with dementia of a more vascular nature. Vitamin D has also been shown to regulate the synthesis of neurotrophins $[47,48]$ and therefore vitamin D hypovitaminosis could potentially promote neuronal death and cognitive decline. Moreover, vitamin D regulates the expression of a number of neurotransmitters including acetylcholine [49] and dopamine [50] and the expression of the enzyme involved in the rate-limiting step of catecholamine synthesis [51], which in turn might impact cognition. In addition, vitamin D inhibits the synthesis of inducible nitric oxide synthase [52], downregulates reactive oxygen species [53], upregulates the antioxidant glutathione [54] and inhibits the expression of pro-inflammatory cytokines [55]. Thus, vitamin D hypovitaminosis might potentiate inflammation and oxidative damage to neurons, hence promoting cognitive deterioration.

Exploratory analysis showed that there was no interaction between 25(OH)D and ApoE $\varepsilon 4$ genotype to modify cortical $A \beta$. It has been shown previously that ApoE $\varepsilon 4$ carriers have a better vitamin $D$ status [56], which could potentially serve to reduce cerebral $A \beta$ burden according to data from animal studies [27, 28]. Moreover, a significant interaction between ApoE $\varepsilon 4$ and 25(OH)D concentrations has been reported in relation to human memory function [57]. Therefore, the links between $25(\mathrm{OH}) \mathrm{D}$ and ApoE $\varepsilon 4$ to govern $A \beta$ pathology is worthy of further research.

The strengths of the current study are the relatively large sample size and the availability of PET $\left[{ }^{18} \mathrm{~F}\right]-$ florbetapir imaging data and plasma $25(\mathrm{OH}) \mathrm{D}$ measurements, providing a more accurate value for vitamin D levels, as opposed to vitamin status assessed through dietary questionnaires. In addition, we considered several cofounders, including a possible interaction between vitamin $\mathrm{D}$ and $\mathrm{ApoE} \varepsilon 4$ status. The limitations of our study included the cross-sectional design, which precluded the examination of the relationship between plasma $25(\mathrm{OH}) \mathrm{D}$ and change in cerebral $A \beta$ load over time. PET scans were also performed throughout the 3-year period of the MAPT; therefore the study design was not truly cross-sectional. The inclusion of the time interval between baseline 25(OH)D measurements and the PET scan as a confounder in the linear regression models probably served to mitigate this bias. Furthermore, we only had data availability for vitamin D status in later life which might perhaps not be the optimal time window for studying the associations between vitamin $D$ and cerebral $A \beta$.

\section{Conclusions}

We have shown here that circulating $25(\mathrm{OH}) \mathrm{D}$ was not associated with cerebral $\mathrm{A} \beta$ in older adults at risk of dementia cross-sectionally. However, a longitudinal observational study including mid-life vitamin D measurements is warranted to examine the relationship between plasma $25(\mathrm{OH})$ $\mathrm{D}$ and cerebral $\mathrm{A} \beta$ accrual over time.

\section{Abbreviations \\ 25(OH)D: 25-Hydroxyvitamin D; AD: Alzheimer's disease; ApoE: Apolipoprotein E; AB: Beta-amyloid; CDR: Clinical Dementia Rating; MAPT: Multidomain Alzheimer Preventive Trial; MMSE: Mini Mental State Examination; n-3 PUFA: Omega-3 polyunsaturated fatty acid; PET: Positron emission tomography; SUVR: Standard uptake value ratio}

\section{Acknowledgements}

The MAPT/DSA Group refers to the following. MAPT Study Group

Principal investigator: Bruno Vellas (Toulouse); Coordination: Sophie Guyonnet; Project leader: Isabelle Carrié; CRA: Lauréane Brigitte; Investigators: Catherine Faisant, Françoise Lala, Julien Delrieu, Hélène Villars; Psychologists: Emeline Combrouze, Carole Badufle, Audrey Zueras; Methodology, statistical analysis and data management: Sandrine Andrieu, Christelle Cantet, Christophe Morin; Multidomain group: Gabor Abellan Van Kan, Charlotte Dupuy, Yves Rolland (physical and nutritional components), Céline Caillaud, Pierre-Jean Ousset (cognitive component), Françoise Lala (preventive consultation), Bertrand

Fougère (Toulouse). The cognitive component was designed in collaboration with Sherry Willis from the University of Seattle, and Sylvie Belleville, Brigitte Gilbert and Francine Fontaine from the University of Montreal. 
Co-investigators in associated centres: Jean-François Dartigues, Isabelle Marcet, Fleur Delva, Alexandra Foubert, Sandrine Cerda (Bordeaux); Marie-Noëlle-Cuffi, Corinne Costes (Castres); Olivier Rouaud, Patrick Manckoundia, Valérie Quipourt, Sophie Marilier, Evelyne Franon (Dijon); Lawrence Bories, Marie-Laure Pader, Marie-France Basset, Bruno Lapoujade, Valérie Faure, Michael Li Yung Tong, Christine Malick-Loiseau, Evelyne Cazaban-Campistron (Foix); Françoise Desclaux, Colette Blatge (Lavaur); Thierry Dantoine, Cécile Laubarie-Mouret, Isabelle Saulnier, Jean-Pierre Clément, Marie-Agnès Picat, Laurence BernardBourzeix, Stéphanie Willebois, lléana Désormais, Noëlle Cardinaud (Limoges); Marc Bonnefoy, Pierre Livet, Pascale Rebaudet, Claire Gédéon, Catherine Burdet, Flavien Terracol (Lyon), Alain Pesce, Stéphanie Roth, Sylvie Chaillou, Sandrine Louchart (Monaco); Kristelle Sudres, Nicolas Lebrun, Nadège Barro-Belaygues (Montauban); Jacques Touchon, Karim Bennys, Audrey Gabelle, Aurélia Romano, Lynda Touati, Cécilia Marelli, Cécile Pays (Montpellier); Philippe Robert, Franck Le Duff, Claire Gervais, Sébastien Gonfrier (Nice); Yannick Gasnier and Serge Bordes, Danièle Begorre, Christian Carpuat, Khaled Khales, Jean-François Lefebvre, Samira Misbah El Idrissi, Pierre Skolil, Jean-Pierre Salles (Tarbes).

MRI group: Carole Dufouil (Bordeaux), Stéphane Lehéricy, Marie Chupin, Jean-François Mangin, Ali Bouhayia (Paris); Michèle Allard (Bordeaux); Frédéric Ricolfi (Dijon); Dominique Dubois (Foix); Marie Paule Bonceour Martel (Limoges); François Cotton (Lyon); Alain Bonafé (Montpellier); Stéphane Chanalet (Nice); Françoise Hugon (Tarbes); Fabrice Bonneville, Christophe Cognard, François Chollet (Toulouse).

PET scan group: Pierre Payoux, Thierry Voisin, Julien Delrieu, Sophie Peiffer, Anne Hitzel, (Toulouse); Michèle Allard (Bordeaux); Michel Zanca (Montpellier); Jacques Monteil (Limoges); Jacques Darcourt (Nice).

Medico-economics group: Laurent Molinier, Hélène Derumeaux, Nadège Costa (Toulouse).

Biological sample collection: Christian Vincent, Bertrand Perret, Claire Vinel (Toulouse).

Safety management: Pascale Olivier-Abbal.

DSA Group

Sandrine Andrieu, Christelle Cantet, Nicola Coley.

\section{Funding}

The MAPT was supported by grants from the Gérontopôle of Toulouse, the French Ministry of Health (PHRC 2008, 2009), Pierre Fabre Research Institute (manufacturer of the omega-3 supplement), Exhonit Therapeutics SA, Avid Radiopharmaceuticals Inc. and in part by a "Investissements d'Avenir" grant from the French National Agency for Research ( $n^{\circ}$ ANR-11-LABX-0018-01). The promotion of this study was supported by the University Hospital Center of Toulouse. The data-sharing activity was supported by the Association Monegasque pour la Recherche sur la maladie d'Alzheimer (AMPA) and the UMR 1027 Unit INSERM-University of Toulouse III. The sponsors had no role.

\section{Availability of data and materials}

The datasets used and/or analysed during the current study are available from the corresponding author on reasonable request.

\section{Authors' contributions}

FN, CH, PDSB, CC, CF, SG and BV contributed to study concept and design. FN, CH, PDSB and CC prepared the manuscript. CC performed statistical analysis. PP and ASS performed PET analyses. IG performed vitamin D analysis. FN, CH, PDSB, CC and BV critically reviewed subsequent drafts. All authors decided on submission. All authors read and approved the final manuscript.

\section{Ethics approval and consent to participate}

Both the MAPT and PET sub-study described in this manuscript were approved by the ethical committee in Toulouse (CPP SOOM II) and have therefore been performed in accordance with the 1964 Declaration of Helsinki and its later amendments. Written consent was obtained from all participants.

\section{Competing interests}

The authors declare that they have no competing interests.

\section{Publisher's Note}

Springer Nature remains neutral with regard to jurisdictional claims in published maps and institutional affiliations.

\section{Author details}

'Gérontopôle, Department of Geriatrics, Toulouse University Hospital, Toulouse, France. ${ }^{2}$ INSERM UMR 1027, Toulouse, France. ${ }^{3}$ University of Toulouse III, Toulouse, France. ${ }^{4}$ Department of Epidemiology and Public Health, CHU Toulouse, Toulouse, France. ${ }^{5}$ University of Bordeaux, Inserm, Bordeaux Population Health Research Center, Team LEHA, UMR 1219, F-33000 Bordeaux, France. ${ }^{6}$ UMR1043 Centre de Physiopathologie Toulouse Purpan, Université de Toulouse, UPS, INSERM, Toulouse, France. ${ }^{7}$ Institut Federatif de Biologie, CHU Toulouse, Purpan University Hospital, Toulouse, France. ${ }^{8}$ UMR 1214, Toulouse Neuroimaging Center, University of Toulouse III, Toulouse, France. ${ }^{9}$ Department of Nuclear Medicine, Toulouse University Hospital, Toulouse, France.

Received: 6 November 2017 Accepted: 3 April 2018

Published online: 25 April 2018

\section{References}

1. Berridge MJ. Vitamin D cell signalling in health and disease. Biochem Biophys Res Commun. 2015;460(1):53-71.

2. Ali A, Cui X, Eyles D. Developmental vitamin D deficiency and autism: putative pathogenic mechanisms. J Steroid Biochem Mol Biol. 2016;175:108-18.

3. Houston DK. Vitamin D and age-related health outcomes: movement, mood, and memory. Curr Nutr Rep. 2015;4(2):185-200.

4. Chiang M, Natarajan R, Fan X. Vitamin D in schizophrenia: a clinical review. Evid Based Ment Health. 2016;19(1):6-9.

5. Rimmelzwaan LM, van Schoor NM, Lips P, Berendse HW, Eekhoff EMW. Systematic review of the relationship between vitamin $D$ and Parkinson's disease. J Park Dis. 2016;6(1):29-37.

6. Pearce SHS, Cheetham TD. Diagnosis and management of vitamin D deficiency. BMJ. 2010;340:b5664.

7. Holick MF. Vitamin D deficiency. N Engl J Med. 2007;357(3):266-81.

8. Annweiler C, Fantino B, Le Gall D, Schott A-M, Berrut G, Beauchet O. Severe vitamin $D$ deficiency is associated with advanced-stage dementia in geriatric inpatients. J Am Geriatr Soc. 2011;59(1):169-71.

9. Littlejohns TJ, et al. Vitamin D and the risk of dementia and Alzheimer disease. Neurology. 2014;83(10):920-8.

10. Etgen T, Sander D, Bickel H, Sander K, Förstl H. Vitamin D deficiency, cognitive impairment and dementia: a systematic review and meta-analysis. Dement Geriatr Cogn Disord. 2012;33(5):297-305.

11. Balion C, et al. Vitamin D, cognition, and dementia: a systematic review and meta-analysis. Neurology. 2012;79(13):1397-405.

12. Feart $C$, et al. Associations of lower vitamin $D$ concentrations with cognitive decline and long-term risk of dementia and Alzheimer's disease in older adults. Alzheimers Dement J Alzheimers Assoc. 2017;13(11):1207-16.

13. Moon $\mathrm{JH}$, et al. Serum 25-hydroxyvitamin D level and the risk of mild cognitive impairment and dementia: the Korean Longitudinal Study on Health and Aging (KLoSHA). Clin Endocrinol. 2015;83(1):36-42.

14. Afzal S, Bojesen SE, Nordestgaard BG. Reduced 25-hydroxyvitamin D and risk of Alzheimer's disease and vascular dementia. Alzheimers Dement J Alzheimers Assoc. 2014;10(3):296-302.

15. Shen L, Ji H-F. Vitamin D deficiency is associated with increased risk of Alzheimer's disease and dementia: evidence from meta-analysis. Nutr J. 2015;14:76.

16. Knekt $P$, et al. Serum 25-hydroxyvitamin d concentration and risk of dementia. Epidemiol Camb Mass. 2014;25(6):799-804.

17. Miller JW, et al. Vitamin D status and rates of cognitive decline in a multiethnic cohort of older adults. JAMA Neurol. 2015;72(11):1295-303.

18. Goodwill AM, Szoeke C. A systematic review and meta-analysis of the effect of low vitamin D on cognition. J Am Geriatr Soc. 2017;65(10):2161-8.

19. Overman MJ, et al. Evaluation of cognitive subdomains, 25hydroxyvitamin D, and 1,25-dihydroxyvitamin D in the European Male Ageing Study. Eur J Nutr. 2016;

20. Karakis I, et al. Association of serum vitamin D with the risk of incident dementia and subclinical indices of brain aging: The Framingham Heart Study. J Alzheimers Dis JAD. 2016;51(2):451-61.

21. Schneider ALC, et al. Vitamin D and cognitive function and dementia risk in a biracial cohort: the ARIC Brain MRI Study. Eur J Neurol. 2014;21(9):1211-8, e69-e70.

22. Stein MS, Scherer SC, Ladd KS, Harrison LC. A randomized controlled trial of high-dose vitamin D2 followed by intranasal insulin in Alzheimer's disease. J Alzheimers Dis JAD. 2011;26(3):477-84. 
23. Przybelski R, Agrawal S, Krueger D, Engelke JA, Walbrun F, Binkley N. Rapid correction of low vitamin D status in nursing home residents. Osteoporos Int J Establ Result Coop Eur Found Osteoporos Natl Osteoporos Found USA. 2008;19(11):1621-8.

24. Annweiler C, Herrmann FR, Fantino B, Brugg B, Beauchet O. Effectiveness of the combination of memantine plus vitamin $D$ on cognition in patients with Alzheimer disease: a pre-post pilot study. Cogn Behav Neurol Off J Soc Behav Cogn Neurol. 2012;25(3):121-7.

25. Rossom RC, et al. Calcium and vitamin D supplementation and cognitive impairment in the women's health initiative. J Am Geriatr Soc. 2012;60(12): 2197-205.

26. Grimm MOW, et al. Impact of Vitamin D on amyloid precursor protein processing and amyloid- $\beta$ peptide degradation in Alzheimer's disease. Neurodegener Dis. 2014;13(2-3):75-81.

27. Briones $T L$, Darwish $H$. Vitamin D mitigates age-related cognitive decline through the modulation of pro-inflammatory state and decrease in amyloid burden. J Neuroinflammation. 2012;9:244.

28. Durk MR, et al. 1a,25-Dihydroxyvitamin D3 reduces cerebral amyloid- $\beta$ accumulation and improves cognition in mouse models of Alzheimer's disease. J Neurosci. 2014;34(21):7091-101.

29. Miller BJ, Whisner CM, Johnston CS. Vitamin D supplementation appears to increase plasma $A \beta 40$ in vitamin D insufficient older adults: a pilot randomized controlled trial. J Alzheimers Dis JAD. 2016:52(3):843-7.

30. Berti $V$, et al. Nutrient patterns and brain biomarkers of Alzheimer's disease in cognitively normal individuals. J Nutr Health Aging. 2015;19(4):413-23.

31. Mosconi $L$, et al. Nutrient intake and brain biomarkers of Alzheimer's disease in at-risk cognitively normal individuals: a cross-sectional neuroimaging pilot study. BMJ Open. 2014;4(6):e004850

32. Vellas B, et al. MAPT study: a multidomain approach for preventing Alzheimer's disease: design and baseline data. J Prev Alzheimers Dis. 2014;1(1):13-22.

33. Del Campo $N$, et al. Relationship of regional brain $\beta$-amyloid to gait speed. Neurology. 2016;86(1):36-43.

34. Joshi AD, et al. Performance characteristics of amyloid PET with florbetapir $F$ 18 in patients with alzheimer's disease and cognitively normal subjects. J Nucl Med Off Publ Soc Nucl Med. 2012;53(3):378-84.

35. Alzheimer's Association. 2016 Alzheimer's disease facts and figures. Alzheimers Dement J Alzheimers Assoc. 2016;12(4):459-509.

36. Oliai Araghi $\mathrm{S}$, et al. BMl and body fat mass is inversely associated with vitamin D levels in older individuals. J Nutr Health Aging. 2015;19(10):980-5.

37. Annweiler $C$, Beauchet $O$. Vitamin D in older adults: the need to specify standard values with respect to cognition. Front Aging Neurosci. 2014;6:72

38. Fleisher AS, et al. Using positron emission tomography and florbetapir F18 to image cortical amyloid in patients with mild cognitive impairment or dementia due to Alzheimer disease. Arch Neurol. 2011;68(11):1404-11.

39. Annweiler C, Annweiler T, Bartha R, Herrmann FR, Camicioli R, Beauchet O. Vitamin $\mathrm{D}$ and white matter abnormalities in older adults: a cross-sectional neuroimaging study. Eur J Neurol. 2014;21(12):1436-e95.

40. Corder EH, et al. Gene dose of apolipoprotein E type 4 allele and the risk of Alzheimer's disease in late onset families. Science. 1993;261(5123):921-3.

41. Annweiler C. Vitamin D-mentia: is vitamin D optional or essential for preventing late-life cognitive decline? J Am Geriatr Soc. 2017;65(10):2155-7.

42. Goodwill AM, et al. Vitamin D status is associated with executive function a decade later: data from the Women's Healthy Ageing Project. Maturitas. 2018;107:56-62.

43. Villemagne $V L$, et al. Amyloid $\beta$ deposition, neurodegeneration, and cognitive decline in sporadic Alzheimer's disease: a prospective cohort study. Lancet Neurol. 2013;12(4):357-67.

44. Annweiler C, Bartha R, Karras SN, Gautier J, Roche F, Beauchet O. Vitamin D and white matter abnormalities in older adults: a quantitative volumetric analysis of brain MRI. Exp Gerontol. 2015;63:41-7.

45. Buell JS, et al. 25-Hydroxyvitamin D, dementia, and cerebrovascular pathology in elders receiving home services. Neurology. 2010;74(1):18-26.

46. Brøndum-Jacobsen P, Nordestgaard BG, Schnohr P, Benn M. 25hydroxyvitamin $D$ and symptomatic ischemic stroke: an original study and meta-analysis. Ann Neurol. 2013;73(1):38-47.

47. Brown J, Bianco Jl, McGrath JJ, Eyles DW. 1,25-dihydroxyvitamin D3 induces nerve growth factor, promotes neurite outgrowth and inhibits mitosis in embryonic rat hippocampal neurons. Neurosci Lett. 2003;343(2):139-43.

48. Naveilhan P, Neveu I, Wion D, Brachet P. 1,25-Dihydroxyvitamin D3, an inducer of glial cell line-derived neurotrophic factor. Neuroreport. 1996; 7(13):2171-5.
49. Sonnenberg J, Luine VN, Krey LC, Christakos S. 1,25-Dihydroxyvitamin D3 treatment results in increased choline acetyltransferase activity in specific brain nuclei. Endocrinology. 1986;118(4):1433-9.

50. Baksi SN, Hughes MJ. Chronic vitamin D deficiency in the weanling rat alters catecholamine metabolism in the cortex. Brain Res. 1982;242(2):387-90.

51. Puchacz E, Stumpf WE, Stachowiak EK, Stachowiak MK. Vitamin D increases expression of the tyrosine hydroxylase gene in adrenal medullary cells. Brain Res Mol Brain Res. 1996;36(1):193-6.

52. Garcion E, Nataf S, Berod A, Darcy F, Brachet P. 1,25-Dihydroxyvitamin D3 inhibits the expression of inducible nitric oxide synthase in rat central nervous system during experimental allergic encephalomyelitis. Brain Res Mol Brain Res. 1997;45(2):255-67.

53. Huang Y-N, Ho Y-J, Lai C-C, Chiu C-T, Wang J-Y. 1,25-Dihydroxyvitamin D3 attenuates endotoxin-induced production of inflammatory mediators by inhibiting MAPK activation in primary cortical neuron-glia cultures. J Neuroinflammation. 2015;12:147.

54. Garcion E, Sindji L, Leblondel G, Brachet P, Darcy F. 1,25-dihydroxyvitamin D3 regulates the synthesis of gamma-glutamyl transpeptidase and glutathione levels in rat primary astrocytes. J Neurochem. 1999;73(2):859-66.

55. Villaggio B, Soldano S, Cutolo M. 1,25-dihydroxyvitamin D3 downregulates aromatase expression and inflammatory cytokines in human macrophages. Clin Exp Rheumatol. 2012;30(6):934-8.

56. Egert S, Rimbach G, Huebbe P. ApoE genotype: from geographic distribution to function and responsiveness to dietary factors. Proc Nutr Soc. 2012;71(3):410-24

57. Maddock J, Cavadino A, Power C, Hyppönen E. 25-hydroxyvitamin D, APOE $\varepsilon 4$ genotype and cognitive function: findings from the 1958 British birth cohort. Eur J Clin Nutr. 2015;69(4):505-8.

\section{Ready to submit your research? Choose BMC and benefit from:}

- fast, convenient online submission

- thorough peer review by experienced researchers in your field

- rapid publication on acceptance

- support for research data, including large and complex data types

- gold Open Access which fosters wider collaboration and increased citations

- maximum visibility for your research: over $100 \mathrm{M}$ website views per year

At BMC, research is always in progress.

Learn more biomedcentral.com/submissions 